\title{
THE INCIDENCE OF INGUINAL HERNIA IN NEWCASTLE CHILDREN
}

\author{
BY \\ GEORGE KNOX \\ From the Department of Child Health, University of Durham, King's College, Newcastle upon Tyne
}

(RECEIVED FOR PUBLICATION APRIL 27, 1959)

The intensive investigations of recent years into the incidence of congenital malformations have largely ignored inguinal hernia. This is surprising in view of its common occurrence and the generally accepted belief that it is congenital in origin even when not apparent at birth.

This paper gives an estimate of the present incidence of inguinal hernia in children in Newcastle upon Tyne and considers certain factors which may influence the risk of its occurrence.

\section{Material}

Almost all children in Newcastle who require hospital care, together with many from surrounding districts, receive it in one of the units associated with the University Department of Child Health. The main material for the present analysis consists of all Newcastle children who had not reached their twelfth birthday and who were admitted to one of these units between 1953 and 1957 for surgical repair of an inguinal hernia. Secondary repair following recurrence and operations in the same child upon a second hernia were excluded, together with femoral, incisional, hiatal and other types of hernia. Surgical repair is therefore part of the definition used for the present purpose. This main group supplied a measure of incidence and of the variation of the risk with age.

One unit recorded with sufficient consistency for analysis the birth rank and birth weight of the affected child and the age of the mother. A consecutive series of 200 children treated for inguinal hernia at this unit was used in assessing the relevance of these factors; 40 of these were also included in the main group and the remaining 160 were from outside the city or, if from Newcastle, were admitted before 1953.

Finally, since there was uncertainty about the existence of a seasonal variation in the birth dates of affected children, the date of birth was reviewed in a much larger number of children treated for hernia and falling outside the two groups described above.

\section{Results}

Incidence. There were 229 Newcastle children treated for inguinal hernia before their twelfth birthday in the five years 1953 to 1957 . They are presented according to the year of operation and year of birth in Table 1 .

TABLE 1

YEAR OF OPERATION AND YEAR OF BIRTH IN 229 NEWCASTLE CHILDREN WITH SURGICALLY TREATED INGUINAL HERNIA

\begin{tabular}{|c|c|c|c|c|c|c|c|}
\hline \multicolumn{7}{|c|}{ Year of Operation } & $\begin{array}{l}\text { Oblique } \\
\text { Totals }\end{array}$ \\
\hline \multirow{19}{*}{$\begin{array}{l}\text { Year } \\
\text { of } \\
\text { Birth }\end{array}$} & & 1953 & 1954 & 1955 & 1956 & 1957 & \\
\hline & 1957 & - & - & - & - & 2 & \\
\hline & 1956 & - & - & - & 2 & 7 & \\
\hline & 1955 & 一 & - & 0 & 11 & 10 & \\
\hline & 1954 & - & 3 & 11 & 14 & 3 & \\
\hline & 1953 & 6 & 12 & 8 & 5 & 5 & \\
\hline & 1952 & 15 & 9 & 5 & 7 & 4 & \\
\hline & 1951 & 3 & 3 & 6 & 2 & 3 & \\
\hline & 1950 & 1 & 7 & 4 & 2 & 0 & \\
\hline & 1949 & 8 & 2 & 6 & 2 & 1 & \\
\hline & 1948 & 6 & 0 & 2 & 0 & 0 & \\
\hline & 1947 & 2 & 0 & 1 & 1 & 2 & \\
\hline & 1946 & 1 & 3 & 1 & 3 & 0 & \\
\hline & 1945 & 2 & 2 & 1 & 2 & 1 & \\
\hline & 1944 & 2 & 1 & 0 & 1 & - & \\
\hline & 1943 & 2 & 1 & 1 & - & - & \\
\hline & 1942 & 1 & 1 & - & - & - & \\
\hline & 1941 & 0 & - & - & - & - & \\
\hline & Totals & 49 & 44 & 46 & 52 & 38 & \\
\hline
\end{tabular}

The last column of this table, giving the oblique totals, shows the time relationships between the 
calendar year of birth and the calendar year of operation. The highest rates of operation were in the first and second calendar years after the year of birth.

This presentation is used because it is the basis on which the incidence of the disease has been calculated. A complementary table (not given) can be constructed from the Registrar-General's reports in which the cells contain the number of children at risk. These figures can be taken as the number of live births in the appropriate year, minus the infant deaths in that year. Thus it follows, for example, that the oblique total 44 in Table 1 represents a number of child years at risk equivalent to the live births of the years 1951 to 1955 less the infant deaths in those years. For the first and last totals (see Table 2) these denominators are halved.

TABLE 2

HERNIA OPERATIONS AND CHILDREN AT RISK BY CALENDAR YEAR OF OPERATION RELATIVE TO THE CALENDAR YEAR OF BIRTH

\begin{tabular}{c|c|c|c}
\hline $\begin{array}{c}\text { Year of Birth } \\
\text { plus : }\end{array}$ & $\begin{array}{c}\text { Hernia } \\
\text { Operations }\end{array}$ & Children at Risk & Rate/1,000 \\
\hline 0 & 13 & $23,793 / 2$ & $1 \cdot 093$ \\
1 & 56 & 23,558 & $2 \cdot 377$ \\
2 & 44 & 23,353 & $1 \cdot 884$ \\
3 & 17 & 23,722 & $0 \cdot 716$ \\
4 & 33 & 24,110 & $1 \cdot 368$ \\
5 & 18 & 24,816 & $0 \cdot 724$ \\
6 & 13 & 26,290 & $0 \cdot 494$ \\
7 & 5 & 27,533 & $0 \cdot 181$ \\
8 & 7 & 27,171 & $0 \cdot 258$ \\
9 & 6 & 27,188 & $0 \cdot 221$ \\
10 & 9 & 25,991 & $0 \cdot 346$ \\
11 & 4 & 23,880 & $0 \cdot 168$ \\
12 & 4 & $21,840 / 2$ & $0 \cdot 366$ \\
\hline Totals & 229 & - & $10 \cdot 198$ \\
\hline
\end{tabular}

When this has been carried out for each of the oblique totals, the results may be added to give an overall estimate of incidence which is unaffected to any serious extent by interaction between the age incidence of operation and the waxing and waning of the birth rate over the period concerned. The details are given in Table 2 where it is shown that the incidence of repaired inguinal hernia in Newcastle children surviving to the age of 12 is $10 \cdot 2 / 1,000$. The $95 \%$ confidence limits of this estimate are $9 \cdot 0 / 1,000$ and $11 \cdot 4 / 1,000$. Since the disease occurs much more frequently in boys than in girls $(\mathrm{M} / \mathrm{F}$ approx. 12/1) an alternative expression of incidence would be 19 per 1,000 boys. Clearly, these estimates refer to the number of children who survive for 12 years and get a hernia, and the proportion of children under 12 affected at any one time will be less.

Age Incidence. The dates of operation, birth and reputed onset of the hernia were recorded with sufficient accuracy to state the exact age at operation in 226 of the 229 children, and the exact age at onset in 191. The distributions are given in Table 3

TABLE 3

AGE DISTRIBUTION OF ONSET AND OF OPERATION IN INGUINAL HERNIA

\begin{tabular}{|c|c|c|c|c|c|}
\hline \multirow{2}{*}{\multicolumn{2}{|c|}{ Age }} & \multirow{2}{*}{$\begin{array}{l}\text { Onset } \\
\text { (No.) }\end{array}$} & \multirow{2}{*}{$\begin{array}{l}\text { Operation } \\
\text { (No.) }\end{array}$} & \multicolumn{2}{|c|}{ Cumulative Incidences of: } \\
\hline & & & & Onset & Operation \\
\hline \multirow[t]{2}{*}{ Months } & $\begin{array}{l}=1 \\
=3 \\
=6 \\
=12 \\
=2 \\
=3 \\
=4 \\
=5 \\
=6 \\
=7 \\
=8 \\
=9 \\
=10 \\
=11 \\
-12\end{array}$ & $\begin{array}{l}31 \\
23 \\
12 \\
12 \\
24 \\
18 \\
23 \\
14 \\
7 \\
5 \\
7 \\
5 \\
4 \\
5 \\
1\end{array}$ & $\begin{array}{r}2 \\
5 \\
7 \\
17 \\
60 \\
29 \\
20 \\
31 \\
16 \\
6 \\
8 \\
5 \\
5 \\
10 \\
4 \\
6\end{array}$ & $\begin{array}{r}1 \cdot 66 \\
2 \cdot 89 \\
3 \cdot 52 \\
4 \cdot 17 \\
5 \cdot 45 \\
6 \cdot 41 \\
7 \cdot 64 \\
8 \cdot 38 \\
8 \cdot 76 \\
9 \cdot 03 \\
9 \cdot 40 \\
9 \cdot 66 \\
9 \cdot 88 \\
10 \cdot 15 \\
10 \cdot 20\end{array}$ & $\begin{array}{r}0 \cdot 09 \\
0 \cdot 31 \\
0 \cdot 64 \\
1 \cdot 40 \\
4 \cdot 10 \\
5 \cdot 42 \\
6 \cdot 32 \\
7 \cdot 72 \\
8 \cdot 44 \\
8 \cdot 71 \\
9 \cdot 07 \\
9 \cdot 29 \\
9 \cdot 75 \\
9 \cdot 93 \\
10 \cdot 20\end{array}$ \\
\hline & & 191 & 226 & - & - \\
\hline
\end{tabular}

together with the calculated cumulative incidences by age both for onset and for operation. These figures are derived by equating the number recorded with the overall incidence.

Fig. 1 demonstrates the relationship between the

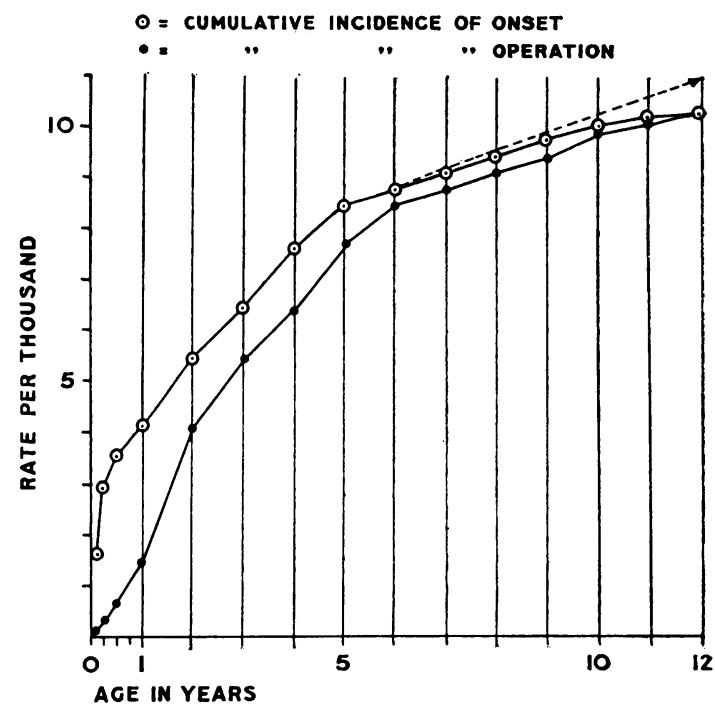

FIG. 1.-Age incidence of inguinal hernia.

cumulative incidence of onset and the cumulative incidence of operation and shows that the waiting time between onset and operation was about one year. The convergence of the lines towards the twelfth year is of course a consequence of the definition used but the picture is such as to give 
TABLE 4

PROPORTIONAL (\%) DISTRIBUTION OF LIVE BIRTHS AND OF CHILDREN WITH INGUINAL HERNIA BY MATER NAL AGE

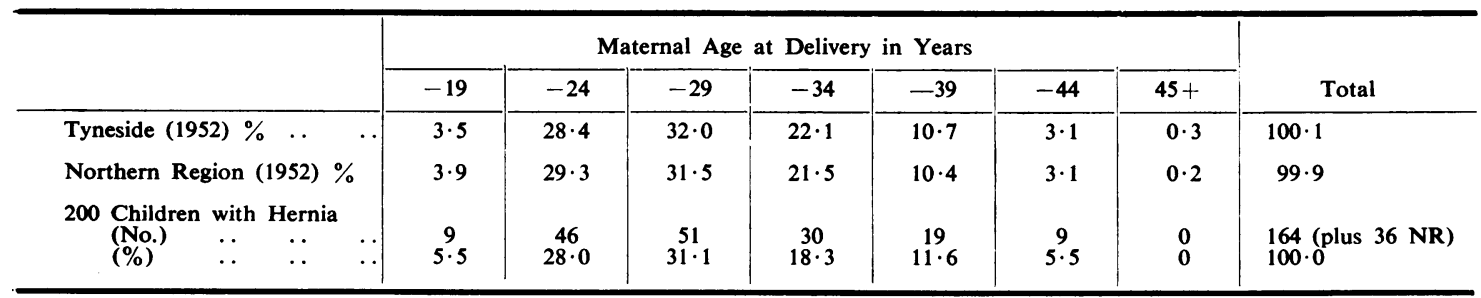

some confidence that at ages under 10 years the estimate of incidence is not greatly short of the true figure. The interrupted line in the figure indicates how the line might proceed if the mean waiting time to operation were consistent by age after starting school and suggests that the true incidence at 12 years might be about a tenth greater than the estimate derived.

Influence of Sex. Among 200 consecutive cases seen at one unit 15 were female. The male/female ratio was $12 \cdot 3: 1$.

The Side Affected. Among the same 200, 58 were on the left side, 127 on the right and 15 were bilateral when seen. The ratio right/left among the 215 individual hernias was $142 / 73=1 \cdot 95: 1$. This pattern was similar in both sexes, the figures for girls being 10 on the right and six on the left.
Maternal Age. The maternal age at the time of admission was recorded in 164 of the 200 cases and the age at delivery was calculable. The distribution is given in Table 4 and compared with proportional distributions for the area in 1952 (Registrar-General, 1952); there are no obvious discrepancies.

Birth Rank. The number of previous live births was recorded for 192 of the 200 consecutive cases at one unit. This distribution is given in Table 5 and compared with figures for England and Wales in 1952 (Registrar-General, 1952). Here there is some suggestion of an increased proportion of first babies among those with inguinal hernia although it does not reach formal significance.

Birthweight. Birthweights as recalled by the mother were recorded in 184 of the 200 cases. The data are presented in Table 6 grouped according to

TABLE 5

PROPORTIONAL (\%) DISTRIBUTION OF LIVE BIRTHS AND CHILDREN WITH INGUINAL HERNIA BY NUMBER OF PREVIOUS LIVE BIRTHS

\begin{tabular}{|c|c|c|c|c|c|c|c|}
\hline & \multicolumn{7}{|c|}{ Previous Live Births } \\
\hline & 0 & 1 & 2 & 3 & 4 or more & Total & Mean \\
\hline $\begin{array}{ccc}\text { England and } & \text { Wales : } \\
\% & \ldots & \ldots\end{array}$ & $39 \cdot 5$ & $30 \cdot 1$ & $15 \cdot 6$ & $7 \cdot 2$ & $7 \cdot 6$ & $100 \cdot 0$ & $1 \cdot 24$ \\
\hline 200 Children $\underset{(\mathrm{O})}{(\mathrm{No})}$ & $\begin{array}{c}84 \\
43 \cdot 7\end{array}$ & $\begin{array}{c}61 \\
31 \cdot 8\end{array}$ & $\begin{array}{c}24 \\
12 \cdot 5\end{array}$ & $\begin{array}{l}10 \\
5 \cdot 2\end{array}$ & $\begin{array}{l}13 \\
6 \cdot 8\end{array}$ & $\begin{array}{l}192 \text { (plus } 8 \text { NR) } \\
100 \cdot 0\end{array}$ & $1 \cdot 07$ \\
\hline
\end{tabular}

TABLE 6

BIRTHWEIGHT DISTRIBUTIONS OF CHILDREN WITH INFANTILE HERNIA AND LATER HERNIA

\begin{tabular}{|c|c|c|c|c|c|c|c|c|c|c|c|}
\hline & \multicolumn{10}{|c|}{ Birthweight (last complete recorded pound) } & \multirow[b]{2}{*}{ Total (No.) } \\
\hline \multirow[b]{2}{*}{ Infantile hernias } & 2 & 3 & 4 & 5 & 6 & 7 & 8 & 9 & 10 & 11 & \\
\hline & 1 & 2 & 4 & 5 & 22 & 11 & 12 & 4 & 0 & 1 & 62 \\
\hline Later hernias & $\mathbf{0}$ & 1 & 3 & 6 & 27 & 40 & 32 & 7 & 4 & 2 & 122 \\
\hline \multirow[t]{4}{*}{ All hernias } & 1 & 3 & 7 & 11 & 49 & 51 & 44 & 11 & 4 & 3 & 184 (plus $16 \mathrm{NR}$ ) \\
\hline & \multicolumn{11}{|c|}{ Mean Birthweights } \\
\hline & & \multirow{2}{*}{\multicolumn{2}{|c|}{$\begin{array}{l}\text { Infantile hernia } \\
\text { Later hernia }\end{array}$}} & $\because$ & & $\because$ & $\begin{array}{r}6.97 \\
7.62 \\
\end{array}$ & & \multirow{2}{*}{\multicolumn{3}{|c|}{$F=8.6 ; P<0.005$}} \\
\hline & & & & & & & $7 \cdot 40$ & & & & \\
\hline
\end{tabular}


the last complete recorded pound, and the mean weight for each group is taken as half a pound more than this value. The mean weight for the 184 children at birth was $7 \cdot 40 \mathrm{lb}$. Table 6 also compares in terms of birthweight children whose hernias were first noted before the first birthday with those noticed afterwards. The mean birthweight of the first group was $6.97 \mathrm{lb}$. and of the second group $7.62 \mathrm{lb}$. The difference of $0.65 \mathrm{lb}$. is statistically significant $(P<0.005)$.

We can compare this group with 429 normal boys born in Newcastle who were the subject of another investigation (Miller, Court, Walton and Knox, 1959), and whose mean birthweight was $7 \cdot 43 \mathrm{lb}$. Considering differences in the method of recording, this is reasonably close to the higher of the previous two figures, but well above the lower one. We can therefore fairly conclude that a high risk of infantile hernia is associated with a low average birthweight.

Birthweight is known to rise with birth rank and this recalls the apparent (although not significant) increased risk of hernia in early birth ranks (see Table 5). It is natural to ask if either the birth weight or birth rank association could be secondary to the other. There is evidence on this point from two sources.

First we have the data of the 429 normal boys analysed by birth rank; in this sample the mean weight of first children was $7 \cdot 23 \mathrm{lb}$. and of later children $7.58 \mathrm{lb}$. The difference between mean birthweights detected by analysis in terms of the timing of a hernia $(0.65 \mathrm{lb}$.) was therefore greater than that detected in a normal sample by means of birth rank $(0.35 \mathrm{lb}$.). This suggests that birthweight rather than birth rank was the factor more

TABLE 7

BIRTH RANK AND AGE AT ONSET OF INGUINAL HERNIA

\begin{tabular}{|c|c|c|c|}
\hline & \multicolumn{2}{|c|}{ Age at Onset } & \multirow[b]{2}{*}{ Total } \\
\hline & First Year & Later & \\
\hline $\begin{array}{l}\text { Birth rank: } \\
\text { First or second } \\
\text { Third or greater }\end{array}$ & $\begin{array}{l}47 \\
19\end{array}$ & $\begin{array}{l}98 \\
32\end{array}$ & $\begin{array}{r}145 \\
51\end{array}$ \\
\hline Total & 66 & 130 & 196 \\
\hline$\%$ First or second & $71 \cdot 2$ & $75 \cdot 4$ & \\
\hline
\end{tabular}

directly associated with altered risk of infantile hernia.

Secondly, and more directly, the children with hernias did not demonstrate a correlation between birth rank and the timing of the hernia. The distribution by birth rank and time of onset in the children in whom both were recorded is given in Table 7. There are therefore double grounds for regarding the association between low birthweight and increased risk of infantile hernia as primary.

Season. The possibility of a seasonal variation in dates of birth was examined. Figures are given in Table 8 for children in the samples already described together with a supplement of extra children whose notes were scanned in the course of extracting data but who were rejected because they fell outside the time and geographical limits set. There was no evidence of a seasonal variation.

\section{Discussion}

There are two aspects of the technique of measurement used in this assessment which might have affected the result. The first is a presumed existence at the age of 12 years of hernias which have not yet come to operation, but reasons for regarding the number as small have been given. The second is that hernia defined in terms of repair precludes those which might have disappeared spontaneously. Most paediatricians and surgeons in Newcastle believe that inguinal hernias do not often resolve spontaneously and so most children reaching hospital come to operation. But general practitioners and parents may not all share this belief and in some children reaching an out-patient department with a symptomless hernia treatment may well be postponed until they have reached a more suitable age for hospital admission. We cannot therefore ignore the possibility that the natural history of the disease may be such that as an estimate of total incidence the present figure is too low. Paterson and Gray (1927), for example, stated that as many as $24 \%$ of hernias in children resolved spontaneously.

This possibility must also be taken into account in our interpretation of the inverse correlation between birthweight and the risk of hernia in infancy. It may be as valid to interpret the effect of birthweight

TABLE 8

MONTH OF BIRTH OF 655 CHILDREN WITH INGUINAL HERNIA

\begin{tabular}{|c|c|c|c|c|c|c|c|c|c|c|c|c|c|}
\hline \multirow[b]{3}{*}{ Children } & \multicolumn{12}{|c|}{ Month of Birth } & \multirow[b]{2}{*}{ Total } \\
\hline & Jan. & Feb. & Mar. & Apl. & May & June & July & Aug. & Sept. & Oct. & Nov. & Dec. & \\
\hline & 65 & 41 & 67 & 62 & 51 & 64 & 49 & 59 & 48 & 54 & 43 & 52 & 655 \\
\hline
\end{tabular}


as expressing a reduced rate of remission as a high rate of occurrence.

There do not seem to be any recent estimates of incidence in known populations of children with which the present estimate can be compared. Keith (1923) estimated that the prevalence of hernia among males of all ages was 20 per 1,000 living, a figure which is reached in Newcastle at the present time among boys surviving to early adult life. Keith's statement of age incidence is difficult to follow but suggests that his estimate of incidence in children is very much less than the current one. Edwards' more recent (1943) estimate of the incidence in adult males (143 of 1,300 service recruits aged 35 to 36 ) strongly suggests that Keith's estimates were based on a low degree of ascertainment.

Collins (1938) supplies some relevant information and from his data may be calculated cumulative incidences of $2 \cdot 7,6 \cdot 2$ and $7 \cdot 1$ per thousand children at ages 5, 10 and 12 respectively. These rates, however, were based on only 43 hernia operations at all ages, and the number occurring in childhood, although not given, is obviously small.

Landers (1938), estimating the incidence of hernia in adults, found an incidence of 16 per 1,000 males aged 16 to 20 years, but once more this was based on small numbers, five cases among 320 examined.

The present estimates of age incidence therefore show no serious discrepancies from the few valid estimates which have already been made, and are presented with some confidence in their relative precision. The only serious objections are the methodological ones which have already been presented; but the figures given stand firmly as minimum incidences and for most purposes, certainly at the earlier ages, can be regarded as absolute measures.

I have not been able to find any previous examination of possible relationships between hernia and the factors tested here except the sex ratio of the disease, which is of course well known, and the preponderance of right over left sided hernias. Paterson and Gray (1927) in their series found 696 males and 77 females and quote another earlier survey with 906 males and 94 females. The M/F ratio in these two series combined is $9 \cdot 4: 1$. The same two series included 1,344 right and 647 left hernias, a ratio of $2 \cdot 1: 1$ compared with the present estimate of 1.95:1.

\section{Summary}

The incidence of inguinal hernia coming to operation was measured in Newcastle children between 1953 and 1957 and found to be 10.2 per 1,000 children of both sexes surviving to their twelfth birthday. The highest rate of onset was in infancy and it fell steadily in succeeding years.

Among possible aetiological factors tested, maternal age and season of birth had no detectable effect and birth rank a doubtful one. The latter may have been secondary to an effect of birthweight: low birthweight was associated with a high incidence of onset in infants but not in older children.

\section{REFERENCES}

Edwards, H. (1943). Proc. roy. Soc. Med., 36, 186

Collins, S. D. (1938). Publ. Hith Rep. (Wash.), 53, 587.

Keith, Sir A. (1923). Brit. J. Surg., 11, 455.

Landers, M. B (1938). Indust Med, 7,671.

Miller, F. J. W., Court, S. D. M., Waiton, W. S. and Knox, E. G (1959). Growing Up. Oxford University Press, London (in press).

Paterson, D. and Gray, G. M. (1927). Archives of Disease in Childhood, $2,328$.

Registrar-General (1952). The Registrar General's Review of England and Wales, 1952, Part II. H.M.S.O., London. 